\title{
María Consuelo Reyna. Periodista y empresaria en la Transición valenciana
}

\author{
Ana María Cervera SÁNCHez \\ Universidad de Valencia \\ amcervera28@hotmail.com
}

Recibido: 28 de abril de 2016

Aceptado: 5 de julio de 2016

\begin{abstract}
Resumen
El pasado 31 de enero Las Provincias, el diario decano de Valencia, celebró su 150 aniversario. Los actos conmemorativos contaron con la asistencia del rey Felipe VI inaugurando la muestra 'La huella de 150 valencianos en el 150 aniversario de Las Provincias' y, sin embargo, faltó un personaje que ha dejado huella en su pasado de casi tres décadas, María Consuelo Reyna.

Reyna, descendiente del fundador de Las Provincias y una de las primeras mujeres al frente de un medio, ha sido voz y testigo de la Transición desde la redacción. Destituida en 1999 por el Consejo integrado por las familias Reyna y Zarranz, la empresa pasa entonces a Vocento, y finaliza un largo ciclo, determinante en la reciente historia valenciana.
\end{abstract}

Palabras clave: Las Provincias; periodista; Transición; Valencia; España.

\section{María Consuelo Reyna. Journalist and businesswoman in the valencian Transition}

\begin{abstract}
Last $31^{\text {st }}$ of January, Las Provincias, the eldest diary in Valencia, held its 150 anniversary. King Felipe VI attended the commemorative acts and inaugurated the exhibition 'La huella de 150 valencianos en el 150 aniversario de Las Provincias', but someone who had left a mark on the diary's 30 years long past wasn't there: María Consuelo Reyna.

Reyna was part of the family of the founder of Las Provincias, and has been voice and witness of the Transition from the newsroom. Dismissed as an editor in 1999 by the Council formed by families Reyna and Zarranz, the business was sold to Vocento, which put an end to a long cycle, essential in the recent valencian history.
\end{abstract}

Keywords: Las Provincias; journalist; Transition; Valencia; Spain.

\section{Referencia normalizada}

Cervera Sánchez, A. M. (2016). María Consuelo Reyna. Periodista y empresaria en la Transición valenciana. Historia y Comunicación Social. Vol 21, número 2, páginas 399-412.

Sumario: 1. Introducción. 2. Estado de la cuestión. 3. Consuelo Reyna, Fata Morgana: el hada cambiante en un periódico que cambia. 4. Conclusiones. 5. Referencias bibliográficas. 
"Esta una profesión muy exigente. Todas lo son, pero la nuestra de manera particular. El motivo es que nosotros convivimos con ella veinticuatro horas al día. No podemos cerrar nuestra oficina a las cuatro de la tarde y ocuparnos de otras actividades. Éste es un trabajo que ocupa toda nuestra vida, no hay otro modo de ejercitarlo. $\mathrm{O}$, al menos, de hacerlo de un modo perfecto".

\section{"Los cínicos no sirven para este oficio”. Ryszard Kapuscinski}

"No se puede comprender ni interpretar la historia política del País Valenciano en los últimos veinte años sin conocer el papel que ha jugado la periodista María Consuelo Reyna"

La Vanguardia: “Una transición que ahora finaliza” 15.09.1999

\section{Introducción}

Las Provincias, decano de la prensa escrita valenciana ha vivido cambios de dinastía, dos repúblicas, una guerra y una dictadura, y alcanzó su centenario coincidiendo con los últimos años del franquismo y la Ley de Prensa de Fraga, en 1966. Ha sido un diario de pocos cambios: en sus propietarios, en su línea, en sus directores y en el público fiel al que se ha dirigido en su larga trayectoria. El político valenciano y "padre" de la Constitución, Emilio Attard, reconoce en La Constitución por dentro, (Castro, 2010: p.337) que "el país tiene contraída una deuda de gratitud con la prensa, con los periodistas que siguieron el proceso constitucional, día a día, más puntuales y exactos que los propios parlamentarios..." En Valencia, desde los últimos años del franquismo, Las Provincias se adaptó a los nuevos tiempos desde su tradicional línea conservadora, con María Consuelo Reyna al frente.

Salvador Barber, veterano periodista, y recién llegado a la redacción del periódico a primeros de los 70, señala en una entrevista personal: "todo lo que quieras saber de la Transición en Valencia, te lo contará María Consuelo". Su despacho fue foro de la oposición, de encuentros, de confidencias al cierre de las ediciones, y depósito de documentos comprometedores. En palabras de Francisco Pérez Puche: "Broseta, Ventura, los Diez de Alaquàs, la Platajunta... todo pasó por allí" (Garrido, Martín y Soler, 1998: p.262). Son los años que marcan la simbiosis más elevada entre periódico y pulso ciudadano. Los años de la campaña de defensa de la Dehesa del Saler y del cauce del Turia, que ganará el periódico y la ciudadanía, frente a los desorbitados proyectos de los alcaldes Rincón de Arellano, López Rosat y Ramón Izquierdo.

Esta insólita cruzada frente a los designios de la alcaldía supone para Las Provincias el reconocimiento como el primer periodismo medioambiental en el ámbito de los géneros de opinión en prensa escrita. María Consuelo Reyna busca colaboradores en este género, e incorpora al periódico el mundo universitario: Mario Gaviria y Josep Vicent Marqués escriben sobre el Saler, y la arquitecta Trinidad Simó sobre 
el amenazado patrimonio urbanístico de la ciudad. Reyna concede una entrevista al periódico Levante en 1981 (Gozálvez, 2004, pp.57-60) en cuya presentación afirma el entrevistador:

"Si yo publicase en esta entrevista todo lo que María Consuelo Reyna se ha dejado en el tintero en vez de lo que ha dicho, quizá hubiese sido la entrevista de mi vida.... Sus comentarios cubren una de las zonas más apasionadamente polémicas del periodismo valenciano, y su personalidad, discutida y discutible como pocas, pone de manifiesto el protagonismo de la mujer en el periodismo local.... Y el sentir de una numerosa audiencia valenciana"

Creadora de campañas y de opinión es, sin embargo, una profesional muy poco estudiada como tal, al margen de los ecos de la Batalla de Valencia. Ella misma ha admitido en conversaciones con la autora que UCD no se gestó en su despacho, "pero estaba en contacto con casi todos los que la crearon". "El mundo político de aquella época era muy pequeño y nos conocíamos todos", recuerda.

Reyna ha sido pionera en el mundo de la comunicación, tanto como periodista como por su cargo en el Consejo y en la Dirección del periódico. Y sin embargo, con la perspectiva de los años, fuera de Valencia no es recordada. Quizá, por su propia personalidad, que reconoce: «nunca me ha interesado estar en los cenáculos». Sea como fuere, el estudio sobre esta mujer periodista de carrera y de vocación, empresaria y muy influyente en la política local y nacional, queda reducido, en un trabajo reciente sobre el peso de las periodistas en la Transición, a dos líneas apresuradas y banales: «En Valencia, Consuelo Reyna, una mujer polémica en esa ciudad, también dirigió un periódico. Su familia era propietaria de Las Provincias» (García-Albi, 2007: p. 82).

Soledad Gallego-Díaz consideraba en el referido trabajo (García-Albi, 2007: p. 124) que lo más preocupante es "que en los medios de comunicación no hay mujeres haciendo opinión, no hay mujeres en los consejos editoriales". El informe de la Asociación de la Prensa de Madrid de 2006 resaltaba que en España, en dicho año, sólo se contaban 18 directoras de periódico, y Carmen del Riego, entonces Presidenta de dicha Asociación, reconoce que las periodistas no han considerado necesario pertenecer a un colectivo, su trabajo era individual.

Sin embargo, en Valencia, desde 1972, Consuelo Reyna ha sido de forma indiscutible una de las periodistas con más influencia desde finales del franquismo, temida y seguida, a partes iguales, por personalidades políticas, sociales y culturales no sólo de la autonomía valenciana, plegadas a su periodismo peculiar. Hablamos de una figura que ha tenido hilo directo con Castellana 3, con Moncloa, con los ministerios y con todo tipo de formaciones políticas locales y nacionales. En su entrevista en Levante en 1981, afirmaba: "Yo los contactos políticos los he tenido siempre sin moverme de mi lugar de trabajo. Quien quiere viene y quien lo desea me llama. La oposición ha pasado por mi despacho tanto como el Gobierno o el partido de Gobierno" 


\section{Estado de la cuestión}

Hace casi dos décadas, el profesor Laguna Platero señalaba la necesidad de profundizar en el conocimiento particularizado de los periodistas, a los que consideraba actores decisivos del proceso social, e insistía en que la historiografía debía abordar investigaciones minuciosas, incluso biográficas, que profundizaran en la implicación contextual de la figura del periodista. Precisamente, la implicación contextual de Reyna en el desarrollo de la Transición en Valencia es absoluta.

Después de una dictadura en la que la comunicación férreamente controlada se centraba en dirigir y adoctrinar a un público "infantil e inmaduro" (Bordería, 2000: p.21), la Transición alumbra una democracia nueva e ilusionante, sin precedentes o referencias en nuestra reciente historia, en la que los medios de comunicación debían llegar a tanta gente y con tantas opciones, como también señala Antonio Laguna.

Aún admitiendo las peculiaridades del camino valenciano de la transición democrática, los periodistas se sintieron en estos años protagonistas del cambio, junto con los nuevos políticos, y no meros espectadores. Lo incierto, los sobresaltos y las esperanzas de la Transición forjaron un frente común de políticos y periodistas a favor de las libertades.

Por otro lado, las nuevas corrientes historiográficas que revisan la Transición española están poniendo el foco en una nueva Historia que busca entender los sujetos, los acontecimientos culturales, la toma de decisiones marcada en estos años por una fuerte improvisación, la expectación y la conflictividad. Todos ellos representando "papeles que resultaron decisivos en el desarrollo del cambio" (Colomer, 2012: p. 267). Señala también el mismo trabajo el vacío de producción historiográfica en el ámbito local sobre la influencia de la prensa en el periodo (Colomer, 2012: p. 269). En este sentido, María Consuelo Reyna es un personaje controvertido, pero indiscutiblemente protagonista.

Este vacío historiográfico en el ámbito valenciano está ocupado hasta ahora, casi exclusivamente, por el estudio esencial del profesor Bordería sobre la prensa durante el franquismo en Valencia, los trabajos de Amador Iranzo Montes sobre el papel de la prensa diaria durante la Transición en Valencia, y los más recientes de María Pareja Olcina estudiando el periódico Mediterráneo y de Carles Senso sobre la revista Valencia Semanal.

El diario Las Provincias es, sin duda, actor político de primera fila en la Transición valenciana. Unas veces ensalzado como artífice y eco de "todos los buenos valencianos"; otras señalado como instrumento manipulador de la realidad a la que aspiraba un País; en ocasiones, alentador fatal de la llamada "Batalla de Valencia". Pero con todo, no ha sido objeto de estudio en una doble vertiente: histórica, como testigo y artífice en buena medida del devenir valenciano en la Transición, y como empresa centenaria adaptada a unos tiempos de cambio. Una empresa, la editorial Federico Doménech, y una familia, los Reyna, representativa de lo esencial y característico del empresariado valenciano. 
Al mismo tiempo, no se ha abordado la figura de una periodista a quien la revista Cambio 16 definió como "subdirectora todopoderosa de Las Provincias, donde escribe a diario una columna que rige la opinión de decenas de miles de valencianos. De hecho, es la única mujer periodista española que crea opinión. Opinión blavera, según el calificativo dado por los nacionalistas y catalanistas a la derecha españolista". Una periodista en un mundo de hombres. Una ejecutiva en los años 70 en un ámbito masculino. Un personaje influyente: "lo más importante es la enorme influencia social que este periódico centenario tiene en su región y la credibilidad que le sigue manteniendo como el número uno" (Blanco, 1990: p.45) y una empresaria, responsable de mantener la rentabilidad de un diario centenario.

Queda pendiente, a fecha de hoy, el estudio de una profesional que, en "la tabla de reflejos condicionados" de Martín Ferrand era equivalente a "periodista valenciana, la magnífica combatiente y perseverante directora de Las Provincias".

\section{Consuelo Reyna, Fata Morgana: el hada cambiante en un periódico que cambia}

El personaje de Consuelo Reyna es complejo, como compleja ha sido la historia de la Transición valenciana. Su perfil en las entrevistas que concede es reservado, discreto, pero contundente en sus convicciones políticas y profesionales, que para ella son muy claras. Reconoce que no escribe para que la interpreten, escribe "para la mayoría de lectores de un periódico regional y de provincias, con el ánimo de conectar con el lenguaje de su público". Y calla mucho más de lo que cuenta.

En 1990, la revista Futuro presentaba bajo el epígrafe "Mujeres con noticia" el personaje de Consuelo Reyna junto con el de otras contadas profesionales de la noticia como la misma Soledad Gallego Díaz o Concha García Campoy. Recordaba que en aquel momento Las Provincias era el décimo en el ranking nacional y el primero de Valencia, con una difusión de 56.000 ejemplares. Hacía 17 años que Reyna había accedido a la subdirección. "El lugar que ocupa el diario lo ha conseguido por ella misma", afirma la autora del reportaje. "Es una mujer valiente, que dice lo que piensa, y nunca ha sufrido contradicción entre los criterios de rentabilidad (...) y su libertad como periodista", prosigue. Consuelo Reyna indicaba en el reportaje que la objetividad no existe. "La sociedad te avala si confía en ti, si la comunicación con ella es perfecta. No puedo dejar de ser empresa y procuro el negocio, porque así tengo más poder y más medios. Creo que es bueno que ambas facetas vayan juntas", reflexiona. ¿Habrían sido distintas las cosas para ella de no haber sido dueña del periódico? "Sí, desde luego".

Los profesores Martí Domínguez -nieto del director de Las Provincias entre 1949 y 1958- y Anna Mateu han estudiado el estilo periodístico de Reyna en su artículo "Periodisme desestabilitzador. L'estil periodístic de M. C. Reyna", publicado en L'Espill: 


\begin{abstract}
"El seu poder per a condicionar la vida política del país va a ser tan gran como determinant, primer com a subdirectora, i a partir de 1992 ja com a directora. A través de les seues columnas, Reyna va disposar d'una tribuna des d'on criticava feroçment aquells amb qui dissentia [...] gran part d'aquest poder derivava del seu estil periodístic, que va tindre una excepcional rebuda entre la clase mitjana valenciana, per ser clar i contundent, unidireccional i reaccionari, i totalment desproveït d'aparell crític".
\end{abstract}

Para el caso de las influyentes palabras de Reyna se podría aplicar la frase de cierre durante 19 años del programa de Walter Cronkite: "así son las cosas". Reconoce que no ha escrito bien en su vida, pero tampoco lo ha pretendido. Remarca en la entrevista: "Me acusaban de destrozar la sintaxis, pero me entendían". El president de la Generalitat Valenciana, Joan Lerma, llegó a decirle: "lo malo que tienes es que se te entiende todo lo que dices".

El perfil de la periodista recoge también los claroscuros que definen el tránsito traumático a la democracia en la ciudad de Valencia, la deriva y la agitación identitaria desde finales del franquismo hasta la aprobación del Estatuto de Autonomía en 1982, y que el periódico reflejaba en su día a día. No en vano "Las Provincias era Valencia." En palabras de Eliseu Climent: "Jo recordé parlar amb Lerma quan ja era president: Escolta, tal cosa... No podem fer-ho perquè la columna de Consuelo dirà... cada día al matí, a les 9 , el que deia Consuelo, no és que anava a missa, no, és que ningú podía eixir-sen'n"'(Crespo, 2005: p.462).

Consuelo Reyna Doménech pertenece a la quinta generación propietaria del periódico Las Provincias. Tataranieta del impresor de La Opinión José Doménech, a quien el Marqués de Campo le vende el derecho a hacer un nuevo periódico que no compartiera la misma cabecera, es la primera periodista profesional del periodismo en la familia, desde que el diario decano arrancara su singladura en 1866. Destinada por sus padres en un principio a la carrera de Farmacia, que detestaba, se matricula en la Escuela Oficial de Periodismo de Madrid, donde se formaron muchas de las mujeres periodistas clave en la incorporación femenina a la profesión durante la Transición. Allí comparte una promoción "espectacular": Martín Ferrand, Amestoy, Balbín, Pilar Salcedo. Recuerda asimismo a la promoción siguiente, que también marcaría la impronta del periodismo en la Transición: Juan Luis Cebrián, Manu Leguineche o Manuel Conde.

Se gradúa con una Memoria sobre Prensa Juvenil, dirigida por el padre Jesús M. Vázquez, profesor de la Escuela y que a la vez dirige la Comisión de Información y Publicaciones Infantiles. Precisamente, cuando Reyna vuelve a Valencia, el padre Vázquez le ofrece ponerse al frente de la Delegación local de la Comisión, en 1964.

La dirigió durante unos meses, con 20 años, y le valió para darle fama de censora, al corregir las publicaciones de dos señeras editoriales valencianas del mundo de la viñeta: Maga y Editora Valenciana. Llevada por la claridad de sus posturas, Reyna contesta en una entrevista que lo volvería a hacer. "Se trataba de prensa infantil y había cosas inapropiadas". Complementa su formación estos años con unos "estudios de Ciencias Empresariales" en Valencia, en una Escuela Empresarial fundada por 
el Instituto Social Patronal del que formaba parte su padre, Enrique Reyna, director gerente de Las Provincias. En 1968 vuelve a Madrid con su familia, cuya actividad principal al margen del periódico, como impresores, mantiene intereses en la capital.

En esta etapa Reyna se integra en una agencia que dio origen a Colpisa: Sapisa, creada por iniciativa de varios diarios independientes regionales y de propiedad familiar. Al principio hace de todo: de secretaria, de redactora, de recadera... y de todo lo que le manda Carlos Sentís. Incluso se ocupa de la sección de Música, una vez en Colpisa. De hecho, lo seguiría haciendo un tiempo en Las Provincias, una vez incorporada al periódico valenciano en 1972.

Mientras tanto, la sociedad valenciana sufre una transformación cualitativa y cuantitativa. Entre 1960 y 1975, el ritmo de crecimiento de la economía valenciana es muy superior al español. La capital ve caer la población en el sector primario (sólo un $2,5 \%$ en 1970), mientras crecen la industria y, sobre todo, los servicios, en el marco de un gran crecimiento de la población y una renovación de la fisonomía urbana. Al mismo tiempo, en los últimos años de la dictadura las fuerzas políticas de la oposición aumentan su presencia. En la izquierda, el PCE es hegemónico en aglutinar los movimientos sociales, mientras que el PSV se configura como el punto de referencia del valencianismo progresista. La democracia cristiana valencianista y otros sectores vinculados a la burguesía, con un cierto perfil autonomista, inician su organización (Saz, 2007: pp. 601-640). Y a este último segmento, mayoritariamente, pertenece el público fiel de Las Provincias.

La familia propietaria, desde 1958 había apostado por la innovación en los talleres e imprenta, frente al retraso tecnológico de la prensa del Movimiento, y continúa en los sesenta aprovechando la bonanza. La empresa editora amplía capital social, manteniendo el núcleo familiar, compuesto por las hermanas Doménech, esposos e hijos, y realiza una campaña para trascender su ámbito de lectores de la capital. El diario decano sigue la línea de buena parte de la prensa nacional en los últimos años del franquismo, situándose en posiciones críticas al régimen, línea en la que fue pionero a nivel local. Lo mismo opina Jaime Millás cuando afirma: "como empresa, Las Provincias se dio cuenta de que era un negocio poder ser el periódico aperturista de la ciudad antes de que la apertura creara otras cabeceras". De 1972 a 1976 su difusión creció un $16 \%$, adelantando con creces a Levante, entonces prensa del Movimiento, (Iranzo, en Caldevilla, 2013: p. 179).

El aperturismo se convierte en una opción reclamada desde las páginas del diario, no tanto a través de sus editoriales sino sobre todo con sus nuevos colaboradores. Y en este marco, "el dinamismo de Las Provincias se acentúa con el desembarco de Consuelo Reyna" (Bordería, 2006: p.341), coincidiendo con la renovación de su plantilla y la entrada de jóvenes periodistas como Fernando Herrero, Salvador Bellver, Pérez Puche, Ricardo Bellveser o Antonio Luque.

Según recuerdan algunos veteranos colaboradores, como el fotógrafo José Penalba, el sucesor en la dirección del periódico, iba a ser el hijo mayor, Federico, aunque no 
era periodista. Federico Reyna fallece en un accidente de automóvil en 1967. "Pero María Consuelo llega, y lo hace muy bien. Moderniza el ambiente".

En agosto de 1970, el presidente del Consejo de Administración, Enrique Reyna, otorga a su hija María Consuelo plenos poderes notariales. En 1972, la joven periodista se incorpora a la redacción ocupando la subdirección vacante por jubilación del veterano Vicente Badía, Consuelo Reyna va asumiendo de hecho la dirección, relegando en cierto modo al director José Ombuena. En palabras de Ricardo Bellveser, recogidas en la revista Historia y comunicación social: "Ombuena comprendió que su tiempo había acabado y empezaba el de Consuelo". O, con una visión menos contundente, la opinión de Federico Martínez Roda en un artículo en Las Provincias, que apunta que en muchos asuntos "se vio espoleado por la que fue su subdirectora, María Consuelo Reyna”.

A partir de este momento, el diario va a servir de apoyo a los movimientos de oposición al franquismo que actuaban en los más diversos frentes: socialistas, nacionalistas, liberales, o demócrata-cristianos. El histórico dirigente de Comisiones, Dionisio Vacas, reconoce la ayuda personal recibida de Reyna y su periódico (Garrido, Martín y Soler, 1998). Y en el otro extremo ideológico, Vicente Navarro de Luján, dirigente de UCD y sobrino de Emilio Attard, apunta en Historia y comunicación social que en los años 73, 74 y 75, “el único baluarte de oposición era Las Provincias, y por ahí pasábamos todos".

Consuelo Reyna recuerda que cuando llegó a Valencia, notó mucho la diferencia entre el periodismo de Madrid y el local. En Las Provincias, cuenta, se hacía la crónica municipal, la de Diputación, la información oficial, "que estaba bien, que se trabajaba, pero que no tenía la viveza que yo había visto en Madrid. Por ejemplo, aquí no había un Oneto, no había un Manu Leguineche, tan apasionados por el periodismo. Yo no pretendía que fuera tanto, pero un poquito sí."

Las Provincias pasó de ser un mero instrumento de comunicación de los dictados oficiales a impulsar un nuevo periodismo que hasta entonces no se practicaba en Valencia: información municipal, movimientos vecinales, los barrios, o entrevistas a políticos en la clandestinidad. Además, abandera una insistente campaña reclamando la integración de España en el Mercado Común.

Reyna echa de menos una "generación intermedia" de periodistas en sus primeros años. Se encuentra con jóvenes periodistas como Salvador Barber y Pérez Puche - que consigue ser "admitido" para informar en los plenos municipales-, y con los clásicos de la redacción. Señala una relación profesional de gran respeto hacia José Ombuena, con quien sostiene que tenía reuniones todos los días, e indica que su padre, como director-gerente, terciaba muy poco en la marcha diaria del periódico. Nunca tuvo que intervenir porque viera en peligro la línea editorial. Recuerda Consuelo Reyna en un artículo de la revista Futuro el sentimiento de provisionalidad que la rodeó en su llegada a la redacción. "Me decían: «al año se cansará de un trabajo que exige 12 y 13 horas, que tontee con el periódico, veremos lo que aguanta»". 
Y sin embargo, aguanta, y empieza a renovar la marcha cotidiana. De la mano de Manuel Sánchez Ayuso, crea una sección semanal, Pulso económico, con jóvenes profesores como Vicent Soler, Aurelio Martínez o José María del Rivero. Trinidad Simó empieza a escribir de forma continuada. Amadeu Fabregat, Ventura Meliá, Damià Mollà, Josep Vicent Marquès, y un largo etcétera, encuentran abiertas las páginas del periódico. Vicent Soler recuerda:

“el fet més trascendental en això d'escriure a la prensa s'esdevé la tardor de 1972 quan una periodista que havia acabat la carrera a Madrid, de nom María Consuelo Reyna, ens cridà a tres joves economistas perquè l'ajudàrem a renovar el diari Las Provincias. Filla de l'amo, volia fer el canvi sense estridències [..]". (Soler, 2011: p.24)

1973 es un año clave en Valencia en el despertar de las reivindicaciones sociales y ciudadanas. Se intensifica la campaña contra la prevista urbanización de la Dehesa del Saler que perseguían los alcaldes Rincón de Arellano y posteriormente López Rosat, y el periódico recoge el tema y lo abandera. El fotógrafo José Penalba recuerda que Consuelo Reyna puso todo el empeño en la campaña: "Me enviaba casi todos los días al Saler, a ver qué imágenes lograba; las lanzábamos bien estudiadas, y estoy muy orgulloso de que se lograra la reacción del público". Al tiempo, Consuelo Reyna dirige sus columnas sobre otra amenaza para la ciudad: el proyecto de una autopista en el viejo cauce del Turia. La revista Blanco y Negro señala:

"Hace algún tiempo, el diario Las Provincias levantó la liebre informativa. Un artículo muy oportuno, firmado por María Consuelo Reyna (...) alertaba a los valencianos acerca del futuro oficialmente previsto para el viejo cauce del rio(...) María Consuelo Reyna enumeraba los graves inconvenientes que acarrearía a la capital, necesitada de espacios verdes, la pérdida de esta superficie (...) El mismo diario valenciano, consciente de la gravedad del problema, ha convocado un concurso periodístico sobre el tema, concurso que está teniendo un éxito sin precedentes en la prensa local"

Desde las páginas de la revista La Marina, Francesc Burguera dice de ella en 1973: "uno viene siguiendo los escritos que María Consuelo Reyna publica en Las Provincias. Una gran periodista se está destapando entre nosotros [...] que además, se está mostrando también como una valenciana preocupada por la comunidad a la que pertenece".

Reyna tiene 28 años en 1974 y manifiesta que en los últimos tiempos de la dictadura "había un objetivo común, que era la libertad y la democracia, y allí sí que éramos todos una piña para ver cómo podíamos publicar lo que fuera". Por eso, se revuelve contra el tópico acuñado como "La Primavera de Las Provincias" que algunos estudios han etiquetado para referirse a los años de aperturismo del periódico entre 1972 y 1978. "No fue en ningún momento un proyecto definido del periódico, sino que vivíamos aquellos tiempos en su día a día, y cada uno lo vivía como quiso". Recuerda que había muchísima ebullición. "Veíamos que íbamos a sufrir una transformación total que no sabíamos cómo enfocar. Todos habíamos nacido en pleno 
franquismo. Por eso, a veces, hacíamos las cosas que hacíamos; porque no sabíamos calibrarlas", concluye.

La muerte de Franco y la coronación de Juan Carlos I evidencian en el contenido del periódico los nuevos aires que imprime Reyna. El 23 de noviembre de 1975 publica la columna "Nueva etapa", recogiendo el discurso del rey ante las Cortes, con un mensaje abierto y esperanzado: "una nueva etapa ha comenzado y esta nueva etapa ha de estar presidida por la concordia nacional (...) Ayer, ante las Cortes se dio un primer paso al que seguirán otros para el efectivo ejercicio de las libertades anunciado por el Rey". El diario se abre al proceso autonómico. En enero de 1976 Carmelo Quintana, presidente de la Audiencia, telefonea a la subdirectora de Las Provincias pidiendo que medie en una agitada manifestación pro-amnistía y estatuto de autonomía que se desarrollaba a las puertas de la Audiencia. Por su intercesión, los manifestantes hacen entrega del documento a Quintana.

El 9 de octubre de 1977 se publica íntegro el poema Poble, de Vicent Andrés Estellés, introducido con un texto en catalán. De hecho, el discurso identitario anticatalanista tiene poco eco en Las Provincias los primeros años de la Transición, expresamente criticado como arma política en las columnas de María Consuelo Reyna, como las publicadas los días 25 de octubre y 31 de diciembre de 1977. Augusto Monzón, uno de los fundadores del Aula Valencianista d'Estudiants recuerda:

"Un company de l'Aula, i jo mateix, arribarem a anar a Las Provincias per proposar a $M C R$ que el seu diari publicara un article nostre expressant el punt de vista nacionalista de manera conciliadora, però al final de l'entrevista ens digué ben a les clares: «cuando volví de Madrid, de estudiar periodismo, yo sabía perfectamente que el valenciano y el catalán son la misma lengua», i davant del nostre astorament va concloure: «pero es que la gente que lee este periódico es muy conservadora»" (Monzón, en Ferrando y Pérez Moragón, 1998: pp. 102-103)

Hasta 1978 el periódico sigue volcado en la defensa del proceso autonómico, a través de editoriales y de la columna de Reyna, que encabezaba bajo el epígrafe, en aquellos momentos, de País, y participa, invitada por Eliseu Climent, como jurado en la edición de los Premis Octubre de los que, posteriormente, se quejaría por haber sido "utilizada".

El periódico, mientras tanto, sigue siendo muy rentable. Frente a la debacle del periódico del Movimiento, Levante, que en estos años lucha por sobrevivir, el diario decano se afianza tanto en la capital como en muchas localidades que ha ido captando frente a Levante. Y en 1978, con la aprobación del Consell Preautonòmic del País Valencià cuya presidencia ostenta el socialista Josep Lluís Albiñana, el desembarco de UCD en Valencia marcará el giro y el devenir futuro del periódico y de la impronta de Consuelo Reyna en la sociedad valenciana, situándose en su línea tradicional "liberal-conservadora" y difundiendo un mensaje identitario en clara oposición al que enarbolaba la izquierda valenciana.

Reyna insiste en que siempre ha defendido los intereses de Valencia, y no iba a cambiar más de 100 años de historia del diario. Alfonso Guerra reconocía que jamás 
había visto un periódico con tal simbiosis con el público: "es inútil que intentemos un periódico en Valencia mientras exista Las Provincias". En 1978, Consuelo Reyna impulsará desde Las Provincias la entrada en UCD de Manuel Broseta, catedrático, abogado, amigo de la familia y colaborador esporádico del periódico desde los primeros 70, y lo hace "de la mano de Emilio Attard". Comienzan ahora los años de la cruenta "Batalla de Valencia", de la que habla como testigo de primera José Luis Torró, director, entonces, de Valencia Semanal en una entrevista publicada en Levante:

"Hay que repartirse las culpas al $50 \%$ porque los periodistas pusieron mucha carne en el asador. Las Provincias ganó la batalla y el otro periodismo, que entonces era muy marginal, hizo un esfuerzo tan grande como inútil (...) Yo creo que María Consuelo hizo lo que ella creía que tenía que hacer (...) Nadie la podrá acusar de no haber sido coherente con sus ideas. Pensaba de un modo concreto y lo defendió con contundencia y apasionamiento".

Queda así esbozada la deriva del periódico que empezó con una Primavera y acabó en una Batalla cruel y baldía. Que dividió y cerró las puertas a un pluralismo que se había sentido representado en algún momento. De cualquier modo, Reyna ha sido retratada por otro periodista histórico, Pérez Benlloch, como

"Una pieza capital para entender nuestro pasado inmediato. [...] Desde su mesa de redacción en el diario decano ha ejercido de confesora de los poderes fácticos, ya políticos, ya económicos, de distinta obediencia, provocando por lo común tanta devoción como pavor. No ha de sorprendernos que en su memoria o archivos se conserven las claves más definitorias de no pocos episodios y personajes [...] También poco faltó para que nos abocasen a la guerra civil. Pero en unas y en otras, y es lo que subrayamos, fue determinante".

Definida como Fata Morgana, hechicera, jugadora de poder, los ecos de su cese reconocían que "ningún personaje contemporáneo ha convulsionado tanto a Valencia -y por ser este el epicentro de un territorio, también al resto del país- como esta periodista agria [...] Ahora, todos los que tuvieron en ella una referencia para bien o para mal se sienten desorientados, que es un estado que precede casi siempre al futuro", explica Miquel Alberola en El País.

Kapuscinski afirma que para ejercer el periodismo, ante todo, hay que ser buen ser humano: "Las malas personas no pueden ser buenos periodistas". Y una entrevista en 1981 recuerda a María Consuelo Reyna que se le tiene por "una especie de Juana de Arco de un reino que no existe, de una lengua que no se habla y de una bandera que no se usa" (Gozálvez, 2004. p.57)

El curso de su vida profesional no acabó en la hoguera, pero fue destituida en 1999 de su cargo de Directora por una "vendetta" a medio camino entre lo político y lo familiar, desde Las Provincias aseguraban que finalizaba un ciclo. "Debemos comenzar el 2000 con otros aires”, añadían. En círculos periodísticos, muchos lo resumían con otras palabras: 'La transición en Valencia ya ha finalizado'. 


\section{Conclusiones}

Durante los últimos años del franquismo, "sectores significativos de la burguesía valenciana marcaron con cierta claridad sus distancias respecto al régimen. Hasta el diario Las Provincias se alineó por entonces con las posiciones liberales y progresistas" (Preston y Saz, 2001. P.280)

El periódico sufrió una evolución a la vez que el proceso político, y se puede observar la suave "transición" entre la prudencia de Ombuena, el empuje y el ansia de cambio de Consuelo Reyna, el variopinto relevo generacional en la redacción e incluso la confianza del propietario y el consejo de administración en los nuevos aires que se imprimían al periódico.

En unos años de cambio e improvisación diaria, el diario decano detecta el sentir de la sociedad, y lo recoge: patrimonio, alcaldía, voces vecinales, reuniones políticas, cultura "no oficial". Escucha y reúne a políticos y propuestas de todo signo, y se convierte en el referente mediático de la ciudad de Valencia.

Consuelo Reyna ha reiterado en múltiples ocasiones, que ella nunca tuvo la sensación de tener el poder, sino el timón del periódico que dirigía. Sólo hacía periódicos, en una empresa que también era suya. Y, por ello, negando que hiciera más política que los políticos, "lo que hice fue defender determinadas cuestiones que para mí eran parte de una sociedad y los políticos dejaban de lado"

Tras las primeras elecciones, y en el marco de la preautonomía valenciana, Las Provincias encuentra su sintonía ideológica en UCD, evolucionando en su comprensión de la lengua y señas de identidad, participando directamente en la controversia y alentando el enfrentamiento conocido como "Batalla de Valencia".

No se puede olvidar la coincidencia centenaria entre el periódico, la burguesía valenciana y los sectores reformistas dentro del propio franquismo, en una ciudad claramente abierta a la expansión económica y enfrentada, en los primeros años 70, a una gestión municipal obsoleta.

Las Provincias, como empresa, se adapta a las circunstancias, crece en ventas frente a su competencia, y vigila el sentir de sus lectores. Reyna ha declarado que las empresas periodísticas tienen derecho a ejercer el poder, pero siempre con un objetivo social, que en este caso, y para ella, serían los intereses valencianos.

\section{Referencias bibliográficas}

ALBEROLA, M. (18.09.1999) "Fata Morgana", El País.

BARBER, S. (22.11.2013). Entrevista realizada por Ana María Cervera

BLANCO, M.L. (1990). "Mujeres con noticia”, Futuro, 44 pp.44-47 
BORDERIA, E. (2006). “Aperturismo avant la lettre en la prensa del franquismo: la burguesía valenciana y la voz disonante de Las Provincias, 1949-1975" en VI Encuentro de Investigadores del Franquismo. Universidad de Zaragoza.

BURGUERA, F. (03.06.1973) La Marina, 15

CASTRO, C. (2010). La prensa en la Transición española. 1966-1978. Madrid: Alianza Editorial

CERDA, P. (31.10.2010) "La culpa de la batalla de Valencia se la reparten al 50\% políticos y periodistas". Levante.

COLOMER, J.C. (2012). "Todo está casi perdonado. A propósito de la Transición, debate historiográfico y propuestas metodológicas". STUDIVM, Revista de Humanidades, 18, p. 267 y 269

CRESPO, A. (2005). "Las Provincias: un diario conservador durante la Transición en Valencia (1972-1982) en Actes del Congrés "La Transició de la dictadura franquista a la democracia" Barcelona.

DOMINGUEZ, M. y MATEU, A. (2012). "Periodisme desestabilitzador. L'estil Periodístic de M.C.Reyna”, L’Espill, 39. pp 21-34

DOMINGO, X. (1987). "Las dos Valencias", Cambio 16, 836 pp.51-66.

ENGUIX, S. (15.09.1999) "La empresa Las Provincias destituye a la directora María Consuelo Reyna", La Vanguardia.

GARCIA- ALBI, I. (2007). Nosotras qué contamos. Barcelona: Plaza y Janés.

GOZALVEZ, P. (2004). Voces de la transición valenciana. Valencia. Gráficas Vernetta

IRANZO, A. (2013). "El diario Las Provincias como elemento clave en el desarrollo de la Transición valenciana", en Caldevilla, D. Comunicando la cultura y ciencia recientes. Madrid: Editorial Visión Libros.

(2014). "Prensa y poder. Las Provincias, actor político central de la Transición valenciana". Historia y Comunicación Social, 19, pp. 535-544.

LAGUNA, A. (1988), "El autor del periódico, un influyente ciudadano", en Actas del I Congrès d'Història de la Ciutat de València.

MARTIN FERRAND, M. (26.07.1996). "Como se ha hecho siempre". $A B C$, p.19

MARTINEZ RODA, F. (20/09/2007). "José Ombuena: el director del Centenario". Las Provincias

MONZON, A. (1998) : "Manuel Sanchis Guarner: records de la Transició", en Ferrando, A. y Pérez Moragón, F.: Manuel Sanchis Guarner: el compromis cívic d'un filòleg . Valencia: Publicacions Universitat de València. pp. 102-103

PENALBA, J.V. (12.02.2015). Entrevista realizada por Ana María Cervera.

PEREZ BENLLOCH, J.J. (10.07.2003) "M.C.Reyna”. El País.

PEREZ PUCHE, F. (1998). En GARRIDO, V., MARTIN, J., y SOLER, M. La transición política en la Comunidad Valenciana. Valencia: Fundación Profesor Manuel Broseta.

PRESTON, P. y SAZ, I. (2001): De la Revolución Liberal a la Democracia Parlamentaria. Valencia (1808-1975). Biblioteca Nueva. Universitat de Valencia. Fundación Cañada Blanch. p.280.

REYNA, M.C. (23.11.1975). "Nueva etapa" Las Provincias 
REYNA, M.C. (25-10.1977 y 31.12.1977) Las Provincias

REYNA, M.C. (30.01.2014). Entrevista realizada por Ana María Cervera

REYNA, M.C. (10.02.2015). Entrevista realizada por Ana María Cervera

SAZ, I. (2007). "Franquismo y democracia en Valencia" en Actas del Simposio "Reino y Ciudad, Valencia en su Historia". Fundación Caja Madrid. pp. 601-640

SOLER, V. (2011): L'ofici de raonar. Valencia: Publicacions Universitat de València, SUEIRO, S. (2013). "Historia y memoria. La España de los años setenta". UNED.

VACAS, D. (1998). "Los sindicatos y su contribución a la recuperación de las libertades". En Garrido, V. Martín, J., y Soler, M.. La transición política en la Comunidad Valenciana. Valencia: Fundación Profesor Manuel Broseta.

V.A. (26.05.1973) "Amenaza para Valencia: una autopista en el viejo cauce del Turia". Blanco y Negro. 